\title{
Incidencia de la política de incentivos tributarios sobre la inversión en el sector minero energético colombiano: un análisis exploratorio de su efectividad*
}

doi:10.11144/Javeriana.cc17-43.ipit

\section{Mario Antonio Ruiz-Vargas}

Universitaria Agustiniana, Bogotá, Colombia. Contador público, especialista en sistemas de control organizacional y de gestión, magíster en auditoría de sistemas. Docente universitario de pregrado y posgrado. Investigador en pensamiento sistémico y responsabilidad y ética social. Docente investigador integrante del grupo de investigación Centro de Investigaciones Agustiniano, Universitaria Agustiniana.

Correo electrónico: mario.ruiz@uniagustiniana.edu.co

\section{Juliana Maritza Velandia-Sánchez}

Universitaria Agustiniana, Bogotá, Colombia. Economista, especialista en evaluación y desarrollo de proyectos. Asistente de investigación del proyecto. Actualmente, coordina el área de competitividad de la empresa R\&R Conocimiento e Innovación.

Correo electrónico: j.velandia@rringenieria.com

\author{
Oscar Saúl Navarro-Morato \\ Universitaria Agustiniana, Bogotá, Colombia. Econo- \\ mista, Universidad Nacional de Colombia. Asistente de \\ investigación del proyecto.
}

Correo electrónico: oscar.navarro@uniagustiniana.edu.co

\footnotetext{
* Artículo de investigación generado como resultado del proyecto de investigación Incentivos tributarios para el sector minero energético en Colombia, del programa de Contaduría Pública de la Universitaria Agustiniana, con radicado 003 de febrero de 2014, desarrollado durante el segundo semestre de 2014.
} 
Resumen El presente artículo pretende hacer un análisis exploratorio sobre la efectividad de la política de incentivos tributarios en el incremento de la inversión extranjera directa (IED) del sector minero energético en Colombia. Se analizaron dos tipos de incentivos que afectan el impuesto a la renta del sector minero energético en Colombia: deducciones por inversión en activos fijos y descuentos tributarios, estableciendo la tasa efectiva de renta (TER) como medida del nivel de tributación del sector y comparando su comportamiento con el de la IED para el período 20002011. Los resultados demostraron que - aunque los incentivos generan un efecto positivo sobre la carga tributaria de las empresas, al disminuir la TER - la efectividad con respecto a la IED no es significativa, pues los precios internacionales de los commodities minero energéticos explican los niveles de IED en el país.

Palabras clave Inversión Extranjera Directa, IED; Tasa Efectiva de Tributación; Incentivos tributarios; sector minero energético

Códigos JEL F21, H21, H23

\section{Effect of the Tax Incentives Policy on the Investments in the Colombian Mining- Energy Sector: An Exploratory Analysis of its Effectivity}

\footnotetext{
Abstract This article aims to carry out an exploratory analysis of the effectivity of the tax incentives policy on the increase of foreign direct investment (FDI) in the miningenergy sector in Colombia. We analyzed two types of incentives which affect the income tax of the mining-energy sector in Colombia: deductions due to investment on tangible fixed assets and tax deductions, establishing the effective income tax rate (EITR) as the measure for the tax levels of the sector and comparing its behavior with that of the FDI for the 2000-2011 period. Results showed that, although incentives create a positive effect on the tax burden of companies by reducing the EITR, their effectivity regard-
}

ing the FDI is not significant, since the international prices of the mining-energy commodities explain the FDI levels in the country.

Keywords Foreign Direct Investment, FDI; effective tax rate; tax incentives; mining-energy sector

JEL Codes F21, H21, H23

\section{Incidência da política de incentivos fiscais sobre o investimento no setor mineiro-energético colombiano: análise exploratória da sua eficácia}

Resumo O presente artigo visa fazer análise exploratória da eficácia da política de incentivos fiscais no acréscimo do investimento estrangeiro direto (IED) do sector mineiro-energético na Colômbia. Analisaram-se dois tipos de incentivo afetando o imposto da renda no setor mineiro-energético na Colômbia: créditos fiscais por investimento em ativos fixos e créditos fiscais, estabelecendo a taxa efetiva de imposto de renda (TER) como medida do crédito tributário do setor e comparando seu comportamento com o da IED para o período 2000-2011. Os resultados mostraram que - embora os incentivos gerar efeito positivo sobre a carga tributaria das empresas, ao diminuir a TER-a eficácia em relação à IED não foi significativa, pois os preços internacionais dos commodities de mineração e energéticos explicam os níveis de IED no país.

Palavras-chave Investimento Estrangeiro Direto, IED; Taxa Efetiva de fiscalização; Incentivos fiscais; setor mineiro-energético

\section{Introducción}

La Inversión Extranjera Directa (IED) se define como la entrada de flujos de capital internacionales. En Colombia, la política de promoción 
de la IED tomó su mayor fuerza después de los años 90, debido principalmente a cambios en el marco normativo que dieron lugar a la disminución en las barreras comerciales y de flujos de capital. Entre las ventajas de atraer IED, se mencionan la transferencia de tecnología, la transferencia de conocimiento, el incremento en la recaudación tributaria, la generación de empleo, etc. (Loungani \& Razin, 2001). Los países receptores también esperan que las inversiones provenientes del exterior generen dinamismo económico, traducido en crecimiento económico y bienestar para sus habitantes.

El objetivo del presente artículo es analizar la efectividad de la política de incentivos tributarios para el caso de la IED en el sector minero energético que en Colombia se considera uno de los motores del desarrollo futuro del país (UPME \& Castillo-E., 2013). En 2013, los flujos de IED del sector correspondían al 52,3\% del total de la IED, con un comportamiento similar durante todo el período de referencia (20012013), lo que significó un crecimiento promedio de más de 19,7\% para el mismo período.

Dadas las características del sector (altos costos de inversión y uso intensivo de capital fijo), entre las políticas para propiciar el crecimiento de la IED, el gobierno ha creado una serie de condiciones desde el punto de vista tributario, como los incentivos tributarios, que buscan mejorar la competitividad del sector para hacerlo más atractivo para las nuevas inversiones. Teniendo en cuenta esto, en el artículo se analizan dos tipos de incentivos: las deducciones por inversión en activos fijos y los descuentos tributarios.
Para tal fin, se ha estructurado el artículo en cinco partes. La primera es esta introducción; la segunda describe la metodología utilizada; la tercera hace una descripción conceptual de los incentivos y muestra en cifras su comportamiento para el sector minero energético; la cuarta se refiere a un análisis de la efectividad de los incentivos en el sector y finalmente, en la quinta parte, las conclusiones.

\section{Metodología}

La metodología utilizada para analizar la efectividad de los incentivos tributarios para promover la inversión en el sector minero energético en Colombia, se basa en Política tributaria para mejorar la inversión y el crecimiento en América Latina, trabajo realizado por Claudio Agostini y Michel Jorratt, para la Comisión Económica para América Latina y el Caribe, CEPAL, publicado en 2013 y en el que se propone un marco metodológico para la evaluación de incentivos tributarios a la inversión, el cual sintetiza las propuestas de Marcelo Tokman R., Jorge Rodríguez C. y Cristóbal Marshall S. (2006), la Organización para la Cooperación y el Desarrollo Económicos, OCDE (2010) y el Banco Mundial (2012). Al contrastar el comportamiento de la tasa efectiva de renta, la inversión extranjera directa y los precios internacionales de los commodities, se establece su nivel de correlación y se evidencia el comportamiento de los costos y beneficios fiscales otorgados.

Para ello, este estudio evalúa la efectividad de los beneficios tributarios que componen las deducciones por inversión en activos fijos y los descuentos tributarios en el impuesto de renta; 
sobre el incremento de la inversión del sector minero energético, mediante el cálculo de la tasa efectiva de renta (TER), para el período comprendido entre 2000 y 2011. La información es obtenida de la Dirección de Impuestos y Aduanas Nacionales (DIAN) sobre las declaraciones de renta y complementarios de las personas jurídicas para cada año gravable.

Para los descuentos tributarios, no se tienen en cuenta los descuentos por donaciones, derogados por la Ley 006 de 1992; descuentos por IVA de bienes de capital, derogados por la Ley 488 de 1998; descuentos por generación de empleo, derogados por la Ley 788 de 2002; por Certificados de Reembolso Tributario, CERT, derogados por la Ley 788 de 2002; ya que según la fecha de derogación, se consideran fuera del rango de estudio.

\section{Justificación de los incentivos tributarios estudiados}

De acuerdo con la literatura, entre los factores determinantes de la IED, están los incentivos tributarios. Los países a menudo prefieren renunciar a parte del ingreso obtenido de los impuestos y reducir las tasas impositivas sobre las sociedades a fin de atraer la IED (Loungani \& Razin, 2001). Hay muchas discusiones sobre la implementación de este tipo de medidas en la política tributaria, debido principalmente a dos aspectos: el primero, la efectividad de su impacto sobre la IED y el segundo, los altos costos sociales a que puede conducir.

En el primer aspecto, Claudio Agostini y Michel Jorratt (2013) hacen un recuento de algunos trabajos sobre diferentes países que muestran evidencia empírica al respecto; en- contraron que la política de incentivos tributarios tiene efectos tanto significativos como no significativos en la IED, con más evidencias en países desarrollados que en países en vías de desarrollo. No obstante, mencionan el trabajo de Claudio Agostini e Ileana Raquel Jalile (2009), que se hizo en once (11) países latinoamericanos y cuyos resultados mostraron que al aumentar en $1 \%$ la tasa de impuesto a las utilidades, la proporción de IED del país disminuye entre $0,75 \%$ y $0,96 \%$.

Por su parte, Jerónimo Roca (2010) señala que la evidencia empírica en países en desarrollo indica que son más relevantes los factores no tributarios y hace referencia a los trabajos de Geeta Batra, Daniel Kaufmann y Andrew H. W. Stone (2002), McKinsey Global Institute (2003), Margaret McMillan, Selina Pandolfi y B. Lynn Salinger (1999), y del World Economic Forum (2005). Por otro lado, varios autores han señalado que las políticas de incentivos tributarios han sido efectivas únicamente cuando:

1. Hay cierta estabilidad política y económica, 2. Hay seguridad jurídica, 3. Se cuenta con mano de obra calificada, 4. Hay buen nivel de infraestructura 5. Hay apertura comercial (Jiménez \& Podestá, 2009).

En cuanto al segundo aspecto, Reint Gropp y Kristina Kostial (2001) indican que estas medidas tienen repercusión en la estructura fiscal que puede ocasionar sistemas tributarios más regresivos, mayores déficits fiscales o una reducción de los servicios públicos. Jerónimo Roca (2010) habla de las repercusiones en el clima de negocios ocasionados por a) la renuncia fiscal, que puede evitar o postergar el desarrollo de inversiones en formación de ca- 
pital y b) cambios en la normatividad tributaria, que convierten el sistema tributario en algo complejo que dificulte su administración. Juan Pablo Jiménez y Andrea Podestá (2009) mencionan efectos como la evasión, la no transparencia en la política fiscal y la distorsión en la asignación de recursos.

Por otro lado, hay otros aspectos determinantes para atraer la IED; distintos estudios han mostrado que los principales factores son el tamaño del mercado, las características de la fuerza laboral, la dotación de materias primas y algunos aspectos institucionales (Agostini \& Jorratt, 2013). Muchos autores señalan que a la hora de atraer flujos de capital externo, los inversionistas consideran en sus decisiones, en segundo lugar el ahorro por beneficios tributarios. La posición actualmente dominante en la literatura sobre incentivos fiscales e inversión es que los factores no tributarios son más importantes como determinantes del monto y la calidad de la inversión que los beneficios tributarios, en particular en los países en desarrollo (Roca, 2010).

\section{Deducciones por inversión en activos fijos}

Los incentivos tributarios generados por las deducciones por inversión en activos fijos, aparecen con la Ley 863 de 2003, que adiciona al estatuto tributario (artículo 68) las deducciones por inversión en activos fijos. El artículo 158-3 del estatuto tributario establece para tal caso:

Las personas naturales y jurídicas contribuyentes del impuesto sobre la renta, podrán deducir el treinta por ciento (30\%) del valor de las inversiones efectivas realizadas solo en activos fijos reales productivos adquiridos, aun bajo la modalidad de leasing financiero con opción irrevocable de compra, a partir del 1 de enero de 2004. Esta deducción solo podrá utilizarse por los años gravables 2004 a 2007 inclusive.

La sanción de la Ley 1111 de 2006 modifica el porcentaje por deducción de inversión en activos fijos y lo incrementa hasta el $40 \%$ a partir de 2007. Posteriormente, la Ley 1370 de 2009 (artículo 10) modifica nuevamente la tarifa, que volvió al 30\%. Finalmente, el artículo 1 de la Ley 1430 de 2010 elimina la deducción especial por inversión en activos fijos reales productivos: “a partir del año gravable 2011, ningún contribuyente del impuesto sobre la renta y complementarios podrá hacer uso de la deducción”.

El incentivo tributario, según referencia Pastor Hamlet Sierra-Reyes (2006), surge a partir de la discusión del proyecto de reforma tributaria de 2003, cuando el gobierno plantea la creación de un instrumento tributario para estimular la inversión y compensar los costos por efecto de la sobretasa en el impuesto sobre la renta y la adopción transitoria del impuesto al patrimonio. Para el sector minero energético, de acuerdo con la International Resources Investment Corporation (2009), este sector presenta ciertas características que requieren un tratamiento tributario especial que se relaciona con los altos costos de inversión y que justifican la creación de este tipo de incentivos tributarios. Entre estas características, la organización menciona que los proyectos son intensivos en capital, especialmente durante la fase de 
construcción, el capital empleado no es transferible ni revendible, el equipo es altamente especializado y usualmente debe ser importado.

En cuanto a la revisión de las cifras, los resultados de la deducción al impuesto de renta por la adquisición de activos fijos productivos para el sector minero — según se evidencia en los análisis realizados por Diana Marcela Parra-Garzón $(2006,2008)$ y Pastor Hamlet Sierra-Reyes (2006) — muestran que es el sector más beneficiado con este incentivo entre los demás subsectores económicos; en 2005, cada una de las 89 empresas de este sector solicitó deducciones por $\$ 9.959$ millones de pesos [valor total \$888.174 millones de pesos], para una inversión promedio en activos fijos cercana a $\$ 33.196$ millones y un menor impuesto promedio de \$3.834 millones de pesos (Parra-Garzón, 2006), este comportamiento ha sido parecido en los años siguientes. Según la DIAN, en 2010, el valor de la deducción fue de $\$ 5.569 .000$ millones de pesos, lo que representa el 48,1\% del total de beneficios tributarios en el país por este ítem. La deducción por inversión en activos fijos ha contribuido en más del 70\% de los beneficios tributarios del sector entre los años 2006-2011 que alcanza un crecimiento promedio por encima del $13 \%$.

El valor de estas deducciones supone inversiones en activos fijos productivos en promedio cada año para el sector, por valor de $\$ 9.454 .000$ millones de pesos, esto significa un crecimiento promedio para el período de referencia equivalente al 11\%. Al comparar esta cifra de inversión con el resto de subsectores económicos, se encuentra que para 2010, del total de la inversión estimada [\$37.842.000 millones de pesos], el sector de minas y energía realizó inversiones por el $48,2 \%$. No obstante, es importante mencionar que en ausencia del beneficio, en 2011 las inversiones cayeron 92,9\%, al pasar de \$18.253.000 millones en 2010 a \$1.303.000 millones en 2011.

Estas cifras muestran importantes crecimientos en bienes de capital para el sector minero y su relevancia con respecto a los demás sectores económicos al usar el beneficio, esto puede evidenciar su importancia para esta actividad económica: hay corresponsabilidad entre los efectos esperados y los objetivos fijados por el incentivo. Esta situación se corrobora con la caída significativa de las inversiones cuando el incentivo fue derogado.

\section{Descuentos tributarios en el impuesto de renta}

El estatuto tributario en su capítulo X: descuentos tributarios, entre los artículos 249-260, describe cómo se aplica o funciona cada uno de los beneficios tributarios que corresponden a los descuentos tributarios. Este estudio se concentra en analizar la razón de la existencia de dos de ellos: descuento por impuestos pagados en el exterior e impuesto sobre las ventas en la importación de maquinaria pesada para industrias básicas, dado que son los que están vigentes o estuvieron vigentes más de la mitad del período de estudio.

Los descuentos tributarios tienen por objeto evitar la doble tributación o incentivar determinadas actividades útiles para el país, que la ley autoriza descontar del impuesto sobre la renta (Sierra-Reyes, 2006). En este caso, estos incentivos se justifican en la medida en que (según 
establece su concepto y funcionamiento) pretenden atraer inversión extranjera directa, al propiciar condiciones tributarias que faciliten el manejo de impuestos sobre rentas de fuente extranjera; así mismo, se deduce que busca que sectores económicos intensivos en bienes de capital, como el minero energético, reduzcan la carga del impuesto al ingreso durante la etapa inicial de producción al realizar inversiones en maquinaria pesada (International Resources Investment Corporation, 2009).

$\mathrm{Al}$ revisar las cifras sobre el valor de los incentivos tributarios que representan los beneficios tributarios para el sector, reportadas por la DIAN, se encuentra que durante el período 2006-2011, estos han crecido por encima del $20 \%$ y han alcanzado una participación promedio del 13,1\% del total de incentivos tributarios en el sector minero energético para los últimos tres años.

En 2011, los descuentos tributarios del sector equivalían al 37,6\% del valor total y durante el período de referencia, esta participación ha sido en promedio de $60,8 \%$. El sector minero energético es el más beneficiado por este incentivo.

\section{Pérdida de recaudación generada por los incentivos tributarios analizados}

En la tabla 1 se muestran los valores calculados por la DIAN sobre el costo fiscal que genera la deducción por la inversión en activos fijos ${ }^{1}$ y las estimaciones de inversión generada al aplicar el incentivo para el período 2006-2011. La pérdida de recaudación anual equivale a $\$ 1.138 .000$

1 La DIAN toma las deducciones generadas y estima o calcula la inversión realizada por las organizaciones. millones de pesos, valor inferior a las inversiones que supone la deducción del impuesto y que asciende a un valor por año de $\$ 9.454 .000$ millones de pesos. Este análisis supone una relación costo-eficiente por parte del beneficio tributario.

\begin{tabular}{lrc}
\hline Año & $\begin{array}{c}\text { Costo } \\
\text { fiscal }\end{array}$ & $\begin{array}{c}\text { Inversiones } \\
\text { estimadas en activos } \\
\text { fijos }\end{array}$ \\
\hline 2006 & 622 & 5.382 \\
2007 & 1.020 & 7.500 \\
2008 & 1.542 & 11.683 \\
2009 & 1.663 & 12.600 \\
2010 & 1.838 & 18.253 \\
2011 & 141 & 1.303 \\
\hline
\end{tabular}

Tabla 1

Deducción por la inversión de activos fijos para el período 2006-2011 (en miles de millones de pesos)

Fuente: DIAN (2011)

Para el caso de los descuentos tributarios, según referencia el Ministerio de Hacienda (2009), la DIAN ha calculado el costo fiscal para el total de los contribuyentes, sin discriminar por subsector económico. Los resultados generales muestran que los costos fiscales tienen el mismo valor que la deducción, esto debido a que los descuentos tributarios afectan directamente el valor del impuesto a pagar, por lo que el monto solicitado equivale al costo fiscal del beneficio (Ministerio de Hacienda, 2011). Suponiendo lo mismo para cada subsector económico, el costo fiscal para el sector minero energético en el período de referencia sería de \$1.427.000 millones de pesos, como se muestra en la tabla 2. Esto equivale al 20\% del 
costo fiscal de las deducciones por inversión en activos fijos.

\begin{tabular}{ccc}
\hline Año & $\begin{array}{c}\text { Descuentos } \\
\text { tributarios }\end{array}$ & Costo fiscal \\
\hline 2011 & 273 & 273 \\
2010 & 309 & 309 \\
2009 & 382 & 382 \\
2008 & 201 & 201 \\
2007 & 137,5 & 137,5 \\
2006 & 124,4 & 124,4 \\
\hline
\end{tabular}

Tabla 2

Descuentos tributarios, 2006-2011 (en miles de millones de pesos)

Fuente: DIAN (2015)

La pérdida de recaudación es uno de los factores que permiten determinar la eficiencia de los incentivos según el análisis costo-beneficio. Este estudio solo muestra las cifras del costo fiscal generadas por la deducción por inversión en activos fijos y por los descuentos tributarios y el impacto directo frente a las inversiones realizadas, según datos de la DIAN.

No obstante, se plantea que en otros estudios se analice este aspecto frente a dos hechos: el primero se relaciona con la rentabilidad financiera que percibe la industria minero energética en el país y el segundo, con los impactos directos e indirectos que esta les genera a la sociedad y al ambiente. Jerónimo Roca (2010) se refiere a esta aproximación como análisis costo-beneficio social de los incentivos fiscales; el autor explica la propuesta de Bruce Bolnick (2004), quien plantea examinar las diferentes combinaciones entre la tasa interna de retorno financiera (privada) y tasa interna de retorno económica (social). En aquellos proyectos con TIR financieras altas es redundante generar un incentivo fiscal, así como en TIR financieras bajas pero con retorno sociales también bajos. Para este caso, probablemente se presente alguna de estas dos situaciones. No obstante sería interesante hacer este tipo de análisis para evaluar con este enfoque la justificación de incentivos tributarios.

\section{Análisis exploratorio de la efectividad de los incentivos tributarios estudiados}

Para el estudio de la efectividad de los beneficios tributarios que corresponden a las deducciones por inversión en activos fijos y los descuentos tributarios en la inversión del sector minero energético; se hizo un análisis con la tasa efectiva de tributación del impuesto a la renta (TER) para el sector y luego se elaboró un modelo econométrico que permitió evidenciar empíricamente la relación entre la inversión extranjera directa (IED) y los cambios en la TER para el período comprendido entre 2000 y 2011.

\section{Tasa efectiva de impuesto a la renta del sector}

Según la literatura, el cálculo y el análisis de tasas impositivas efectivas están entre los métodos más usuales para evaluar los resultados y el impacto de la política tributaria en la situación económica del país. Con ellos es posible sintetizar la incidencia de los beneficios o sobrecargas existentes en la legislación y determinar la verdadera carga tributaria, y vislumbrar el efecto de la tributación sobre las decisiones de los 
agentes económicos (Ávila-Mahecha \& LeónHernández, 2006).

Entre los tipos de tasas más utilizados para analizar los efectos de los beneficios tributarios en las cifras de inversión está la tasa efectiva promedio, que resulta apropiada para medir la carga tributaria neta y su distribución entre los sectores de la economía. Esta tasa se define como el porcentaje de los impuestos pagados en el último año sobre las utilidades antes de impuestos (Ávila-Mahecha \& León-Hernández, 2006).

En la presente investigación, su estimación se basó en la metodología desarrollada por Javier Ávila-Mahecha e Ivonne Rocío León-Hernández (2006), para el trabajo de investigación Una nota acerca de la tarifa efectiva del impuesto sobre la renta en Colombia para el año gravable 2004. La información para el cálculo de la tasa se obtuvo de las declaraciones de renta y complementarios de personas jurídicas para el sector minero energético que reportan a la DIAN, entre 2000 y 2011.

Las siguientes variables componen el indicador:

- Impuesto Neto de Renta, INR

- Renta Líquida Gravable, RLG

- Deducciones Tributarias por Inversión en Activos Fijos, DIAF

- Rentas Exentas, RE

- Descuentos Tributarios, DT

Aplicando la siguiente fórmula:

$$
\mathrm{TER}=\frac{\mathrm{INR}}{\mathrm{RLG}+\mathrm{BT}}
$$

En donde, la Tasa Efectiva de Renta (TER) resulta de dividir el Impuesto Neto de Renta (INR) entre la Renta Líquida Gravable (RLG) y los Beneficios Tributarios (BT), que corresponde a las Deducciones Tributarias por Inversión en Activos Fijos (DIAF), Rentas Exentas (RE) y Descuentos Tributarios (DT).

Según los resultados, el valor de la TER del sector minero energético, para el año gravable 2011 fue de 32,46\%. En promedio, para el período de estudio, la tarifa real fue de $28,5 \%$, inferior a la tarifa de impuesto de renta nominal establecido por la ley, teniendo en cuenta que antes de 2006 la tasa nominal era de 35\% y fue disminuyendo hasta llegar al 33\%, sin incluir la sobretasa. Para analizar el efecto de los incentivos tributarios sobre la tarifa real, también se calculó esta, sin tener en cuenta los beneficios tributarios; se observa que la tasa promedio real del período aumentó 4,89 puntos, teniendo un valor de 33,34\%.

También se encuentra que si no se realizaran deducciones por inversión en activos fijos, la tarifa del impuesto aumentaría en promedio 2,44 puntos, siendo de 30,89\%; mientras que si se hace el mismo ejercicio con los descuentos tributarios, la variación es casi de cero, pues la tarifa promedio sería de $28,58 \%$. De este análisis, se puede inferir que las deducciones por inversión en activos fijos generan un impacto mayor en la reducción del impuesto en comparación con los descuentos tributarios, cuyo impacto es casi nulo. En la tabla 3 se muestran los resultados: 


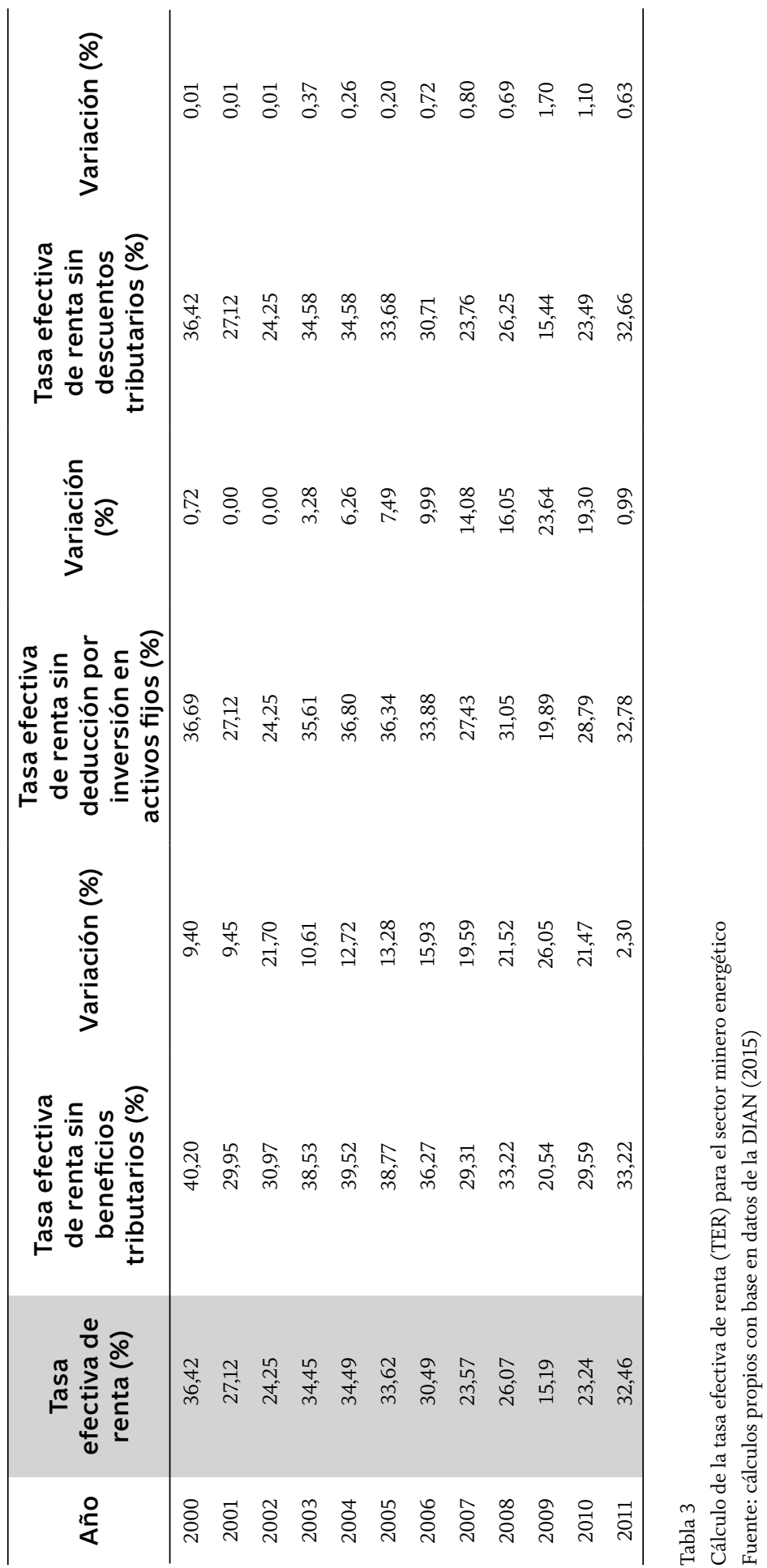




\section{Comportamiento de variables seleccionadas}

Para analizar la relación de causalidad de la política de beneficios tributarios con el crecimiento de la Inversión Extranjera Directa (IED) del sector minero energético en el período 2000-2011, las gráficas 1 a 4 presentan el comportamiento tendencial y de correlación de las diferentes variables de estudio que fueron analizadas.

En comparación con el PIB del sector, la conducta de la IED del sector exhibe una tendencia similar para cada uno de los años analizados y muestra un crecimiento promedio año a año muy parecido para cada variable que corresponde a $22,4 \%$ y $18,3 \%$ respectivamente, y una participación de la IED del sector del 24\% en el PIB nacional. En cuanto al comportamiento de la TER y la IED del sector, la relación existente resulta negativa, como se esperaría según lo señala la teoría; no obstante, el resultado del coeficiente de correlación parece mostrar que no hay evidencia estadística de que la relación entre las dos variables sea causal lineal: alcanza apenas un coeficiente de 0,135. Lo mismo sucede al contrastar la TER y el PIB del sector con un coeficiente cercano al 0,0497.

Finalmente, al revisar cómo se comporta la IED ante los cambios en los precios de los commodities que incluyen el petróleo, el gas natural, el carbón y el níquel, por tener la mayor participación en las exportaciones del país, se encontró que hay una correlación positiva entre las variables, cercana al $87,7 \%$.

De igual forma, al revisar el nivel de correlación entre el gasto del gobierno central y el precio de las materias primas - para la cual tomamos el índice de precios de la ener- gía ${ }^{2}-$, se tiene un comportamiento similar al que se observa entre la IED en el sector minero energético y los precios del petróleo crudo. Es decir, estadísticamente, el comportamiento de los precios de los commodities tiene un nivel de significancia más alto, que explica mejor el crecimiento de la IED en el sector durante el período analizado, que el encontrado entre la TER y la inversión para el período referenciado.

\section{Conclusiones}

$\mathrm{Al}$ establecer la efectividad de los incentivos con respecto al incremento de la inversión extranjera directa (IED), se encuentra que la tasa efectiva de renta no es significativa, mientras que los precios internacionales de los commodities son los que muestran una mayor relevancia en el crecimiento de la IED del sector

$\mathrm{Al}$ analizar la política de beneficios tributarios para el sector minero energético, se evidencia que para los incentivos analizados (deducciones por inversión en activos fijos y por los descuentos tributarios), el minero energético es el sector económico que obtiene las mayores deducciones y descuentos; esto genera beneficios tributarios que les reducen a las empresas del sector en promedio (años 20002011) la carga tributaria en cerca de 4 puntos porcentuales; las deducciones por inversión en activos fijos son las que mayor efecto tienen en la tarifa del impuesto a la renta: esto generó

\footnotetext{
2 El índice de precios de la energía, reportado por el Banco Mundial, consiste en una canasta ponderada de los precios promedio de carbón, petróleo crudo y gas natural, para el período 2000-2004, exportados por los países en desarrollo.
} 


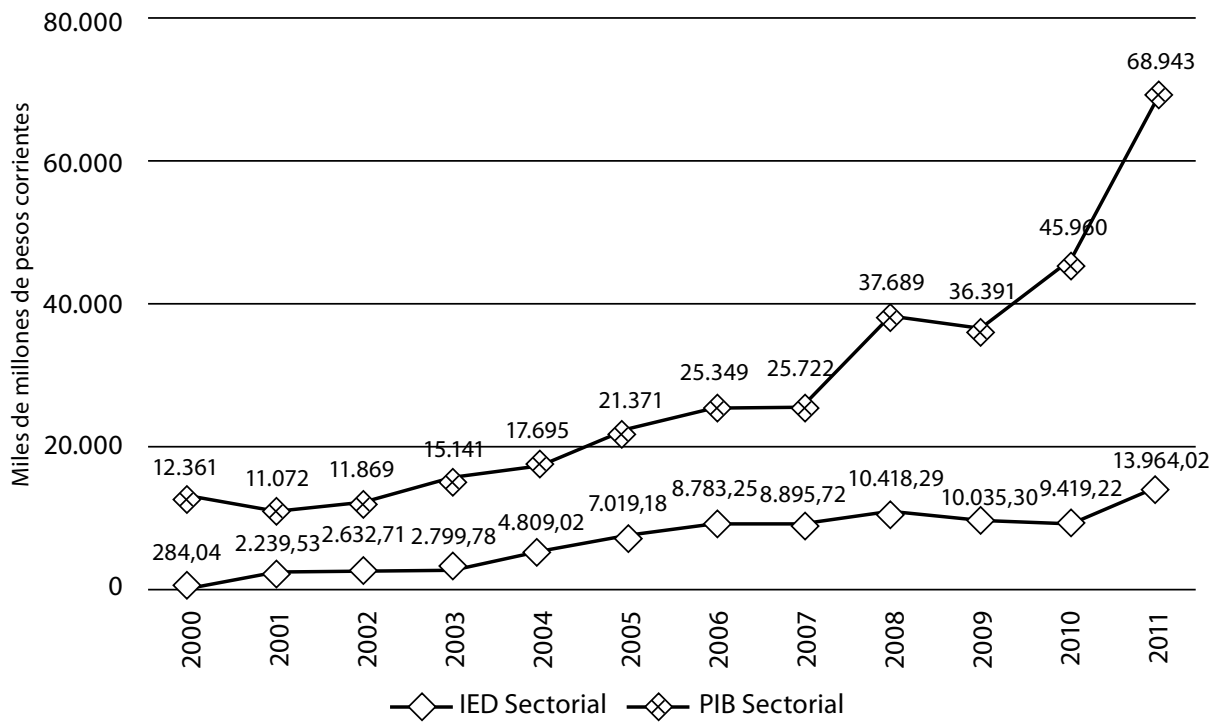

Gráfica 1

Comportamiento de la IED y el PIB para el sector minero energético, entre 2000 y 2011 (en miles de millones de pesos) Fuente: cálculos propios con base en datos del Banco de la República y el Departamento Administrativo Nacional de Estadística, DANE (2015)

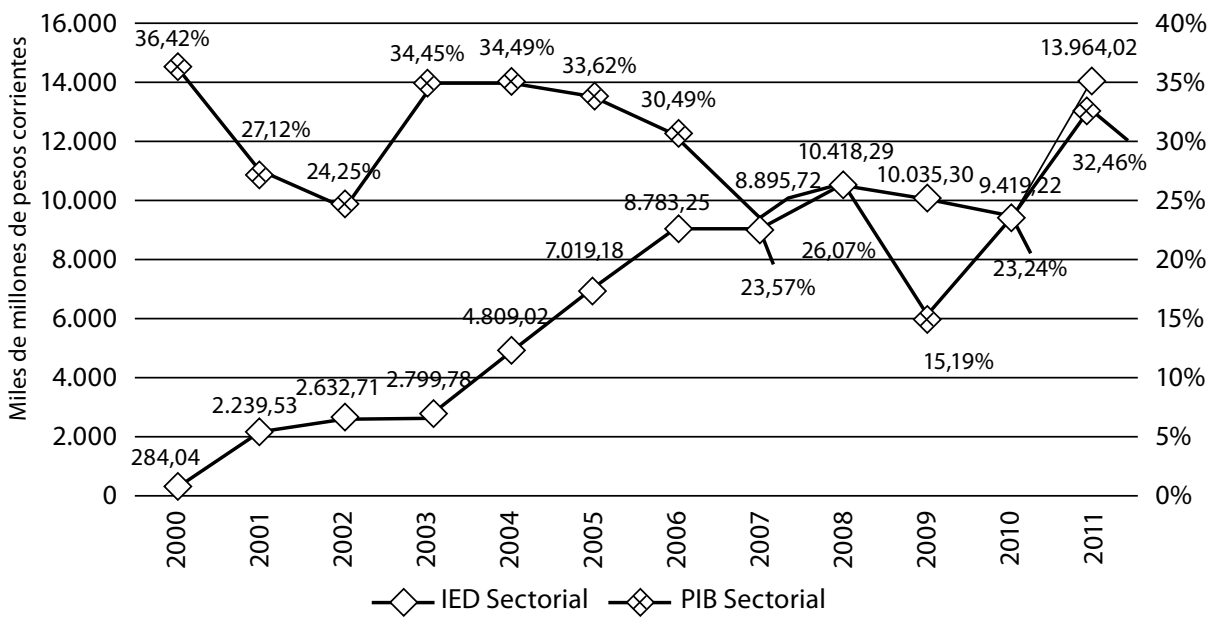

Gráfica 2

Comportamiento de la IED y la TER para el sector minero energético, entre 2000 y 2011 (en miles de millones de pesos) Fuente: cálculos propios con base en datos del Banco de la República y el Departamento Administrativo Nacional de Estadística, DANE (2015) 


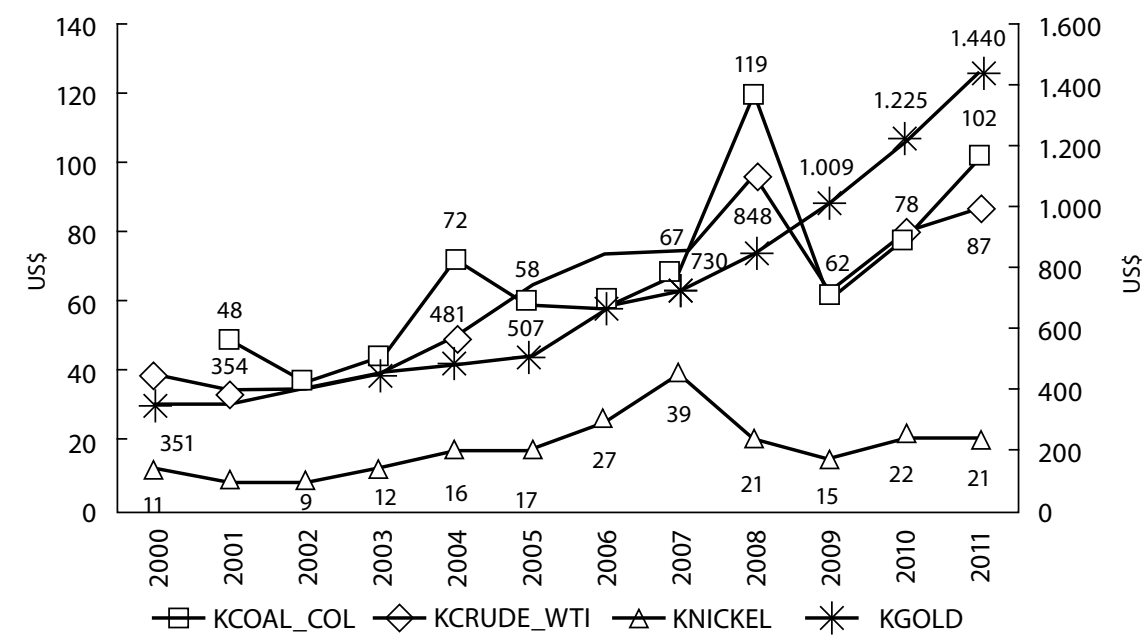

Gráfica 3

Precio de los commodities entre 2000 y 2011 (en US\$ constantes de 2000)

Convenciones: KCOAL_COL: Carbón Colombiano, dólares por tonelada; KCRUDE_WTI: Valor promedio del petróleo referencia WTI [West Texas Intermediate], dólares por barril; KNICKEL: Níquel, dólares por tonelada; KGOLD: Oro, dólares por onza.

Fuente: Banco Mundial (2015)
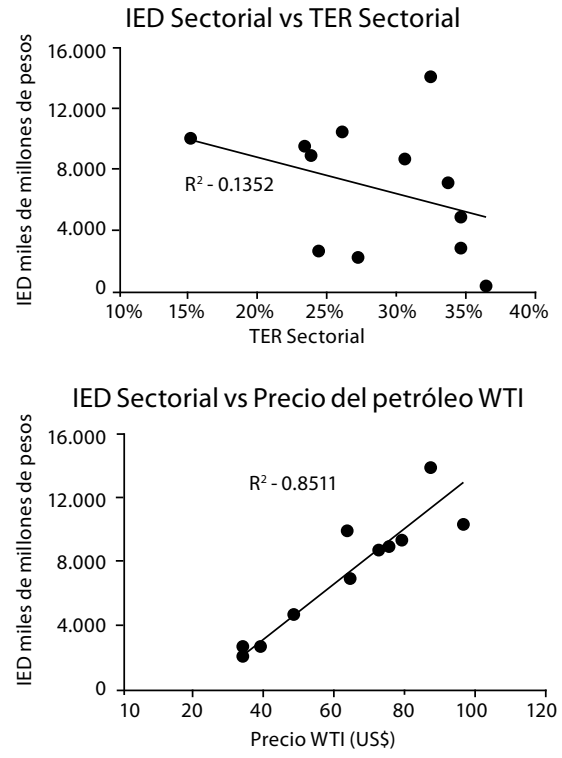

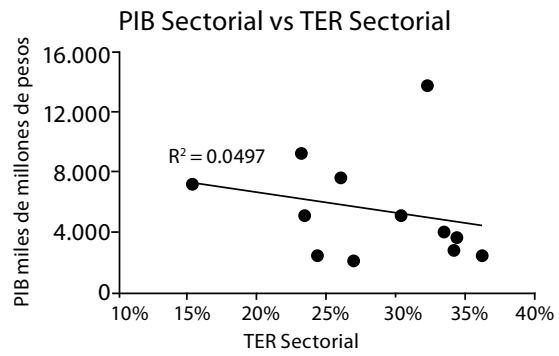

Gasto del gobierno vs Índice de precio

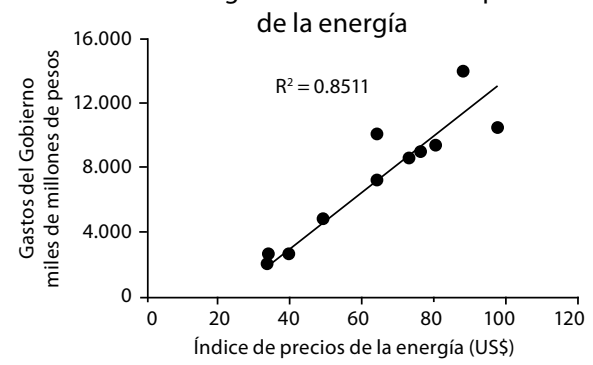

\section{Gráfica 4}

Correlaciones entre las diferentes variables de estudio para el período 2000-2011

Fuente: cálculos propios con base en datos del Banco de la República y el Departamento Administrativo Nacional de Estadística, DANE (2015) 
inversiones hasta por $\$ 18.200 .000$ millones de pesos en 2010.

No obstante, al analizar la efectividad de los incentivos como determinantes del incremento de la inversión extranjera directa (IED), se encuentra que la tasa efectiva de renta no es estadísticamente significativa; mientras que los precios de los commodities tienen mayor relevancia en el crecimiento de la IED. Frente a estos resultados habría que considerar los beneficios tributarios solo como una herramienta que compone un conjunto de estrategias para atraer inversión de calidad y que hay otros determinantes como la estabilidad institucional y jurídica, y el fortalecimiento de actividades de innovación y desarrollo que tienen un mayor peso en las decisiones del inversionista, según las tendencias de política. Los incentivos tributarios solo se justifican para solucionar las fallas del mercado y su aplicación debe ser focalizada y momentánea.

\section{Referencias}

Agostini, Claudio \& Jalile, Ileana Raquel

(2009). Efectos de los impuestos corporativos en la inversión extranjera en América Latina. Latin American Research Review, 44 (2), 84-108. Disponible en: http://lasa.international.pitt.edu/LARR/ prot/fulltext/vol44no2/Agostini-Jalile_44-2. pdf

Agostini, Claudio \& Jorratt, Michel (2013).

Política tributaria para mejorar la inversión y el crecimiento en América Latina. Santiago de Chile: Naciones Unidas, Comisión Económica para América Latina y el Caribe, CEPAL, Serie Macroeconomía del Desarrollo 130. Disponible en: http://repositorio.cepal.org/bitstream/ handle/11362/5361/1/LCL3589_es.pdf Ávila-Mahecha, Javier \& León-Hernández, Ivonne Rocío (2006). Una nota acerca de la tarifa efectiva del impuesto sobre la renta en Colombia para el año gravable 2004. Bogotá: Cuadernos de trabajo, Oficina de Estudios Económicos de la Dirección de Impuestos y Aduanas Nacionales, DIAN. Disponible en: http:/www.dian.gov.co/descargas/ servicios/OEE-Documentos/Cuadernos/ TarifaEfectivaEnRenta.pdf

Banco de la República (2015). Servicio electrónico de estadísticas. Disponible en: http://www.banrep.gov.co/es/-estadisticas Banco Mundial (2012). El gasto tributario en Colombia: una propuesta de evaluación integral y sistemática de este instrumento de política pública. Washington, Bogotá: Banco Internacional de Reconstrucción y Fomento / Banco Mundial, Región de América Latina y el Caribe. Disponible en: http:// documentos.bancomundial.org/curated/ es/945121468022751656/pdf/658790REPL ACEMOUBLIC00final0version.pdf

Banco Mundial (2015). Servicio electrónico de estadísticas. Disponible en: http://datos. bancomundial.org/

Batra, Geeta; Kaufmann, Daniel \& Stone, Andrew H. W. (2002). Voices of the Firms 2000: Investment Climate and Governance. Findings of the World Business Environment Survey (WBES). Discussion Draft. Washington: World Bank. Disponible en: http://socsci2.ucsd.edu/ aronatas/project/ academic/voicesfirms2k_fulltext.pdf 
Bolnick, Bruce (2004). Effectiveness and Economic Impact of Tax Incentives in the SADC [Southern African Development Community] Region. Technical Report submitted to United States Agency for International Development/ Regional Center for Southern Africa's, USAID/RCSA. February. Disponible en: http://pdf.usaid. gov/pdf_docs/Pnacy929.pdf

Colombia (1989). Decreto 624 de 1989, por el cual se expide el Estatuto Tributario de los impuestos administrados por la Dirección General de Impuestos Nacionales o Estatuto Tributario Nacional. Diario Oficial, 38.756, 30 de marzo de 1989. Disponible en: http:// estatuto.co, http://www.secretariasenado. gov.co/senado/basedoc/estatuto_tributario. html

Colombia (1992). Ley 006 de 1992, por la cual se expiden normas en materia tributaria se otorgan facultades para emitir títulos de deuda pública interna, se dispone un ajuste de pensiones del sector público nacional y se dictan otras disposiciones. Diario Oficial, 40.490, 30 de junio de 1992. Disponible en: http://www.secretariasenado.gov.co/senado/ basedoc/ley_0006_1992.html

Colombia (1998). Ley 488 de 1998, por la cual se expiden normas en materia tributaria y se dictan otras disposiciones fiscales de las entidades territoriales. Diario Oficial, 43.460, 28 de diciembre de 1998. Disponible en: http://www.secretariasenado.gov.co/senado/ basedoc/ley_0488_1998.html

Colombia (2002). Ley 788 de 2002, por la cual se expiden normas en materia tributaria y penal del orden nacional y territorial; y se dictan otras disposiciones. Diario Oficial, 45.046, 27 de diciembre de 2002. Disponible en: http://www. secretariasenado.gov.co/senado/basedoc/ ley_0788_2002.html

Colombia (2003). Ley 863 de 2003, por la cual se establecen normas tributarias, aduaneras, fiscales y de control para estimular el crecimiento económico y el saneamiento de las finanzas públicas. Diario Oficial, 45.415, 29 de diciembre de 2003. Disponible en: http://www.secretariasenado.gov.co/senado/ basedoc/ley_0863_2003.html

Colombia (2006). Ley 1111 de 2006, por la cual se modifica el estatuto tributario de los impuestos administrados por la Dirección de Impuestos y Aduanas Nacionales. Diario Oficial, 46.494, 27 de diciembre de 2006. Disponible en: http://www. secretariasenado.gov.co/senado/basedoc/ ley_1111_2006.html

Colombia (2009). Ley 1370 de 2009, por la cual se adiciona parcialmente el estatuto tributario. Diario Oficial, 47.578, 30 de diciembre de 2009. Disponible en: http:// www.secretariasenado.gov.co/senado/ basedoc/ley_1370_2009.html

Colombia (2010). Ley 1430 de 2010, por medio de la cual se dictan normas tributarias de control y para la competitividad. Diario Oficial, 47.937, 29 de diciembre de 2010. Disponible en: http://www. secretariasenado.gov.co/senado/basedoc/ ley_1430_2010.html

Colombia, Departamento Administrativo Nacional de Estadística, DANE (2015). Servicio electrónico de estadísticas. 
Disponible en: http://www.dane.gov.co/ index.php/estadisticas-por-tema/cuentasnacionales/cuentas-nacionales-trimestrales Colombia, Ministerio de Hacienda (2011). Principales beneficios tributarios en el impuesto sobre la renta y en el impuesto al valor agregado (IVA) año gravable 2010. Disponible en: http://www.camara.gov.co/ portal2011/gestor-documental/search_result

Conferencia de las Naciones Unidas sobre Comercio y Desarrollo, UNCTAD (2013). Informe sobre las inversiones en el mundo 2013: las cadenas de valor mundiales: inversión y comercio para el desarrollo. Nueva York: UNCTAD. Disponible en: http://unctad.org/es/PublicationsLibrary/ wir2013overview_es.pdf

Dirección de Impuestos y Aduanas Nacionales, DIAN (2015). Servicio electrónico de estadísticas. Disponible en: http://www.dian. gov.co/contenidos/cifras/estadisticas.html Gropp, Reint \& Kostial, Kristina (2001). La IED y los impuestos a las sociedades. ¿Armonización o competencia tributaria? Revista Finanzas y Desarrollo, 38 (2), 10 13. Disponible en: https://www.imf.org/ external/pubs/ft/fandd/spa/2001/06/pdf/ gropp.pdf

International Resources Investment Corporation, IRIC (2009). Informe final preparado para el Gobierno de Colombia: apoyar la política de mejoramiento de la productividad y competitividad del sector minero colombiano. Bogotá: International Resources Investment Corporation, IRIC. Disponible en: http://www.simco.gov.co/
LinkClick.aspx?fileticket $=$ MVXgeC $\% 2 F o \%$ 2Fus\%3D\&tabid=97

Jiménez, Juan Pablo \& Podestá, Andrea (2009). Inversión, incentivos fiscales y gastos tributarios en América Latina. Santiago de Chile: Naciones Unidas, Comisión Económica para América Latina y el Caribe, CEPAL, Serie Macroeconomía del Desarrollo 77. Disponible en: http://www. cepal.org/publicaciones/xml/2/35732/ Serie_MD_77.pdf

Loungani, Prakash \& Razin, Assaf (2001). ¿Qué beneficios aporta la inversión extranjera directa? Revista Finanzas y Desarrollo, 38 (2), 6-9. Disponible en: https://www.imf. org/external/pubs/ft/fandd/spa/2001/06/ pdf/loungani.pdf

McKinsey Global Institute (2003). New Horizons: Multinational Company Investment in Developing Countries. San Francisco: McKinsey Global Institute. Disponible en: http://www. mckinsey.com/business-functions/businesstechnology/our-insights/new-horizons-formultinational-company-investment McMillan, Margaret; Pandolfi, Selina \& Salinger, B. Lynn (1999). Promoting Foreign Direct Investment in Labor-Intensive Manufacturing Exports in Developing Countries. Consulting Assistance on Economic Reform-II, CAER-II Discussion Paper 42. Harvard Institute for International Development. Disponible en: http://www.cid.harvard.edu/archive/caer/ dpapers.html, http://pdf.usaid.gov/pdf_ docs/Pnacf585.pdf Organización para la Cooperación y el Desarrollo Económicos, OCDE (2010). 
Choosing a Broad Base - Low Rate Approach to Taxation. París: Organización para la Cooperación y el Desarrollo Económicos, OCDE. Disponible en: http://www.oecd. org/ctp/tax-policy/choosing-a-broadbase-low-rate-approach-to-taxation9789264091320-en.htm

Parra-Garzón, Diana Marcela (2006). Efecto de la deducción por inversión en activos fijos reales productivos en el impuesto sobre la renta: año gravable 2005. Bogotá: Cuadernos de trabajo, Oficina de Estudios Económicos de la Dirección de Impuestos y Aduanas Nacionales, DIAN. Disponible en: http:// www.dian.gov.co/descargas/servicios/OEEDocumentos/Cuadernos/Cambios_Efecto_ de_la_deduccion.pdf

Parra-Garzón, Diana Marcela (2008). Deducción por inversión en activos fijos año gravable 2007: una aplicación del gasto tributario. Bogotá: Cuadernos de trabajo, Oficina de Estudios Económicos de la Dirección de Impuestos y Aduanas Nacionales, DIAN. Disponible en: http:// www.dian.gov.co/descargas/Servicios/OEEDocumentos/Cuadernos/Cuaderno_de_ trabajo_031.pdf

Roca, Jerónimo (2010). Evaluación de la efectividad y eficiencia de los beneficios tributarios. Washington: Banco Interamericano de Desarrollo, BID, Documento de debate IDB-DP-136. Disponible en: http://www.iadb. org/wmsfiles/products/publications/ documents/35259019.pdf

Sierra-Reyes, Pastor Hamlet (2006). Efecto de la deducción del 30\% por inversión en activos fijos reales en el recaudo del impuesto sobre la renta en Colombia en el año gravable 2004. Bogotá: Cuadernos de trabajo, Oficina de Estudios Económicos de la Dirección de Impuestos y Aduanas Nacionales, DIAN. Disponible en: http:/www.dian.gov.co/ descargas/servicios/OEE-Documentos/ Cuadernos/deduccion.pdf

Tokman, Marcelo; Rodríguez, Jorge \& Marshall, Cristóbal (2006). Las excepciones tributarias como herramienta de política pública. Estudios Públicos, 102, 69-112. Disponible en: http://cieplan.cl/media/ publicaciones/archivos/298/Estudio.pdf Unidad de Planeación Minero Energética, UPME \& Castillo-E., Orlando (2013). Plan Nacional de Ordenamiento Minero, PNOM. Capítulo: el sector minero colombiano a futuro: potencial y competitividad por mineral, transformaciones y encadenamientos productivos. Bogotá: UPME. Disponible en: http://www1.upme.gov.co/sites/ default/files/forum_topic/3655/files/ sector_minero_colombiano_futuro_ potencial_competitividad_mineral_ transformaciones_encadenamientos_ productivos.pdf

World Economic Forum, WEF (2005). The Global Competitiveness Report 2004/2005. London: Palgrave-MacMillan.

- Fecha de recepción: 17 de junio de 2015

- Fecha de aceptación: 15 de junio de 2016

- Disponible en línea: 30 de junio de 2016 
126 / VOL. 17 / NO. 43 / ENERO-JUNIO 2016

\section{Para citar este artículo}

Ruiz-Vargas, Mario Antonio; Velandia-Sánchez, Juliana Maritza \& Navarro-Morato, Oscar Saúl (2016). Incidencia de la política de incentivos tributarios sobre la inversión en el sector minero energético colombiano: un análisis exploratorio de su efectividad. Cuadernos de Contabilidad, 17(43), 109-126. http://dx.doi. org/10.11144/Javeriana.cc17-43.ipit 